\title{
The Chebyshev spectral method for variable order fuzzy fractional advection diffusion equation by using Mittag-Leffer law
}

Prashant Pandey ${ }^{1}$ and Sunil Kumar ${ }^{2}$

${ }^{1}$ Indian Institute of Technology Banaras Hindu University

${ }^{2}$ National Institute of Technology

July 30,2020

\section{Hosted file}

Manuscript.pdf available at https://authorea.com/users/317329/articles/473198-the-chebyshevspectral-method-for-variable-order-fuzzy-fractional-advection-diffusion-equation-byusing-mittag-leffer-law

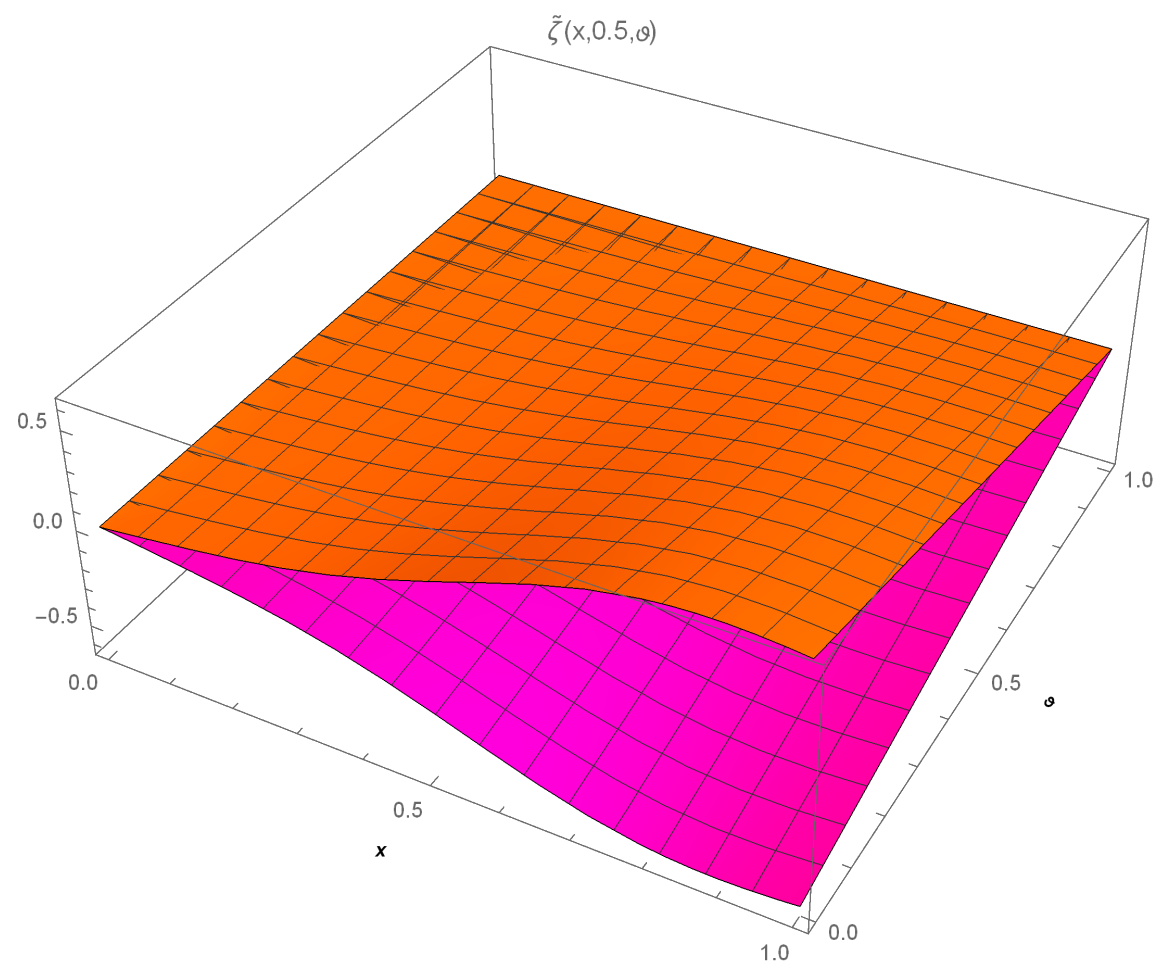



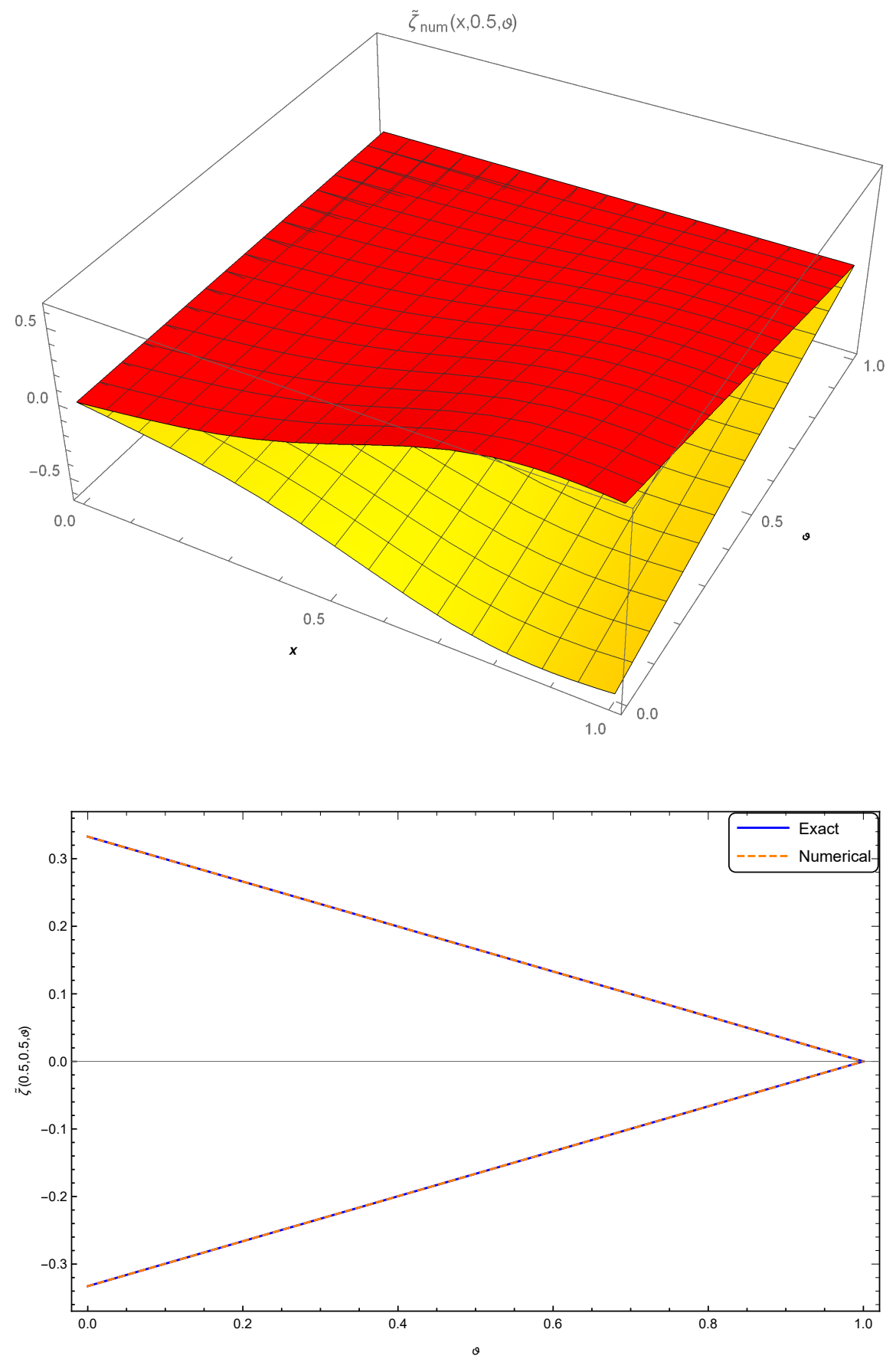

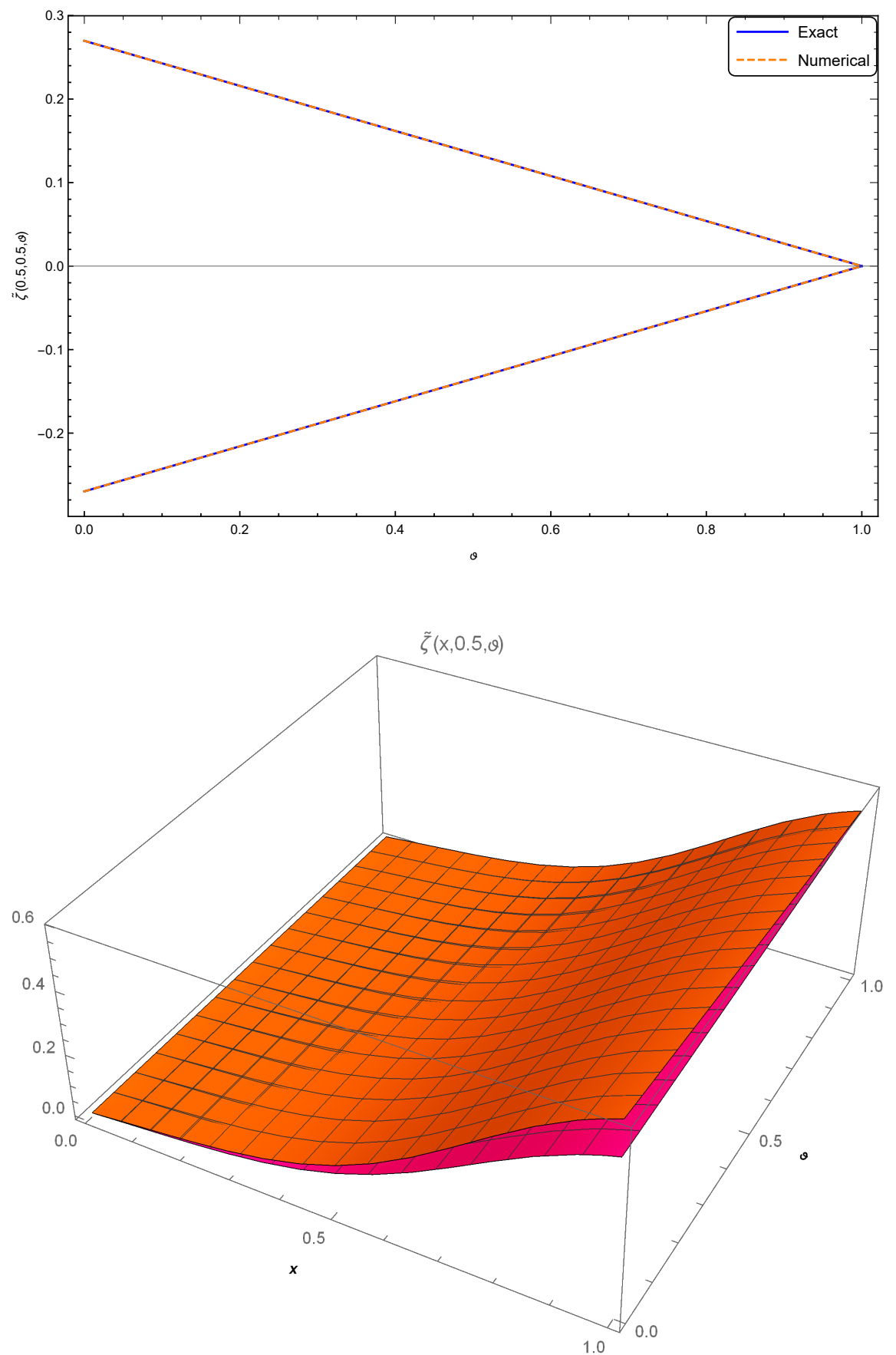

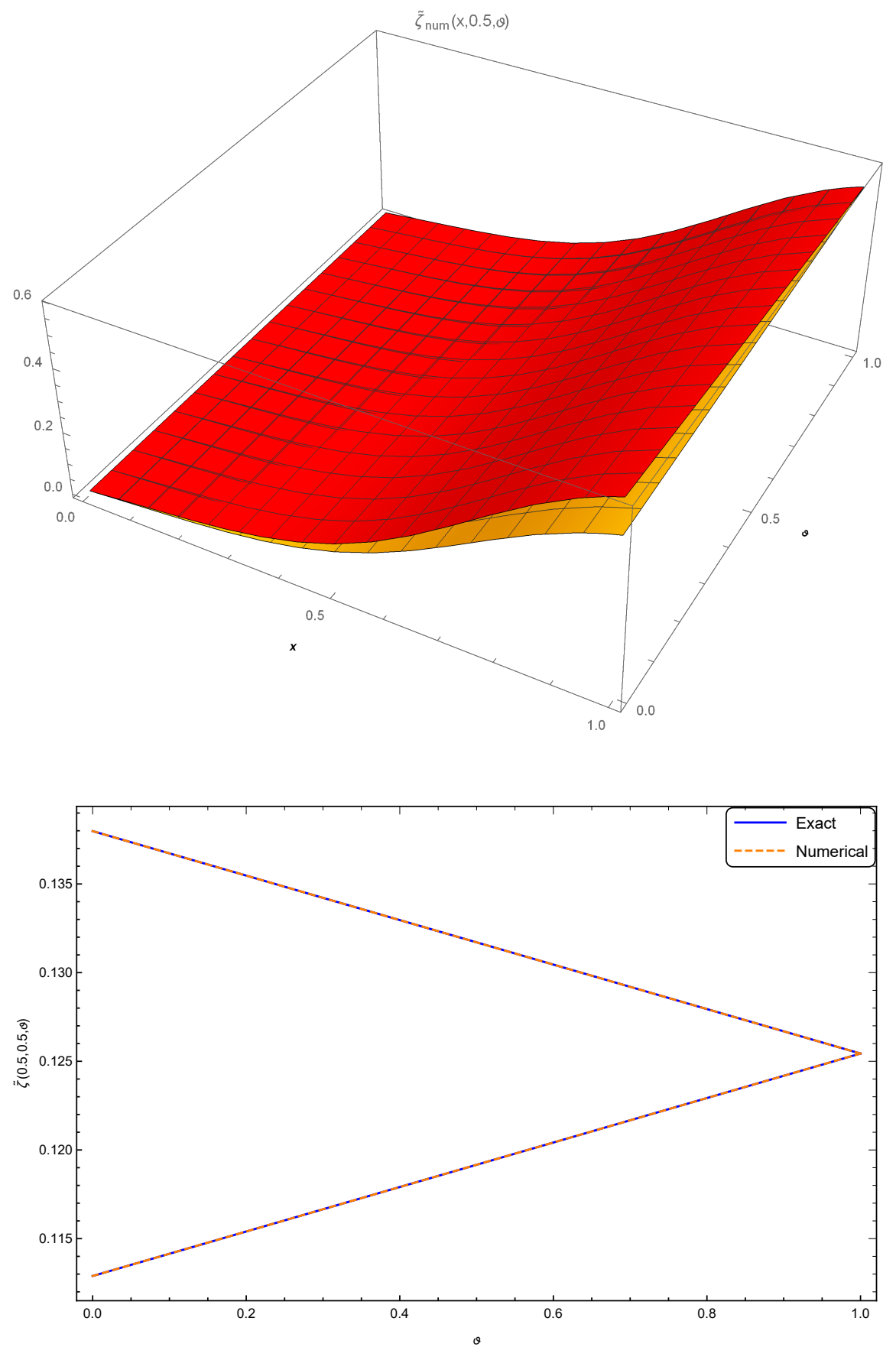

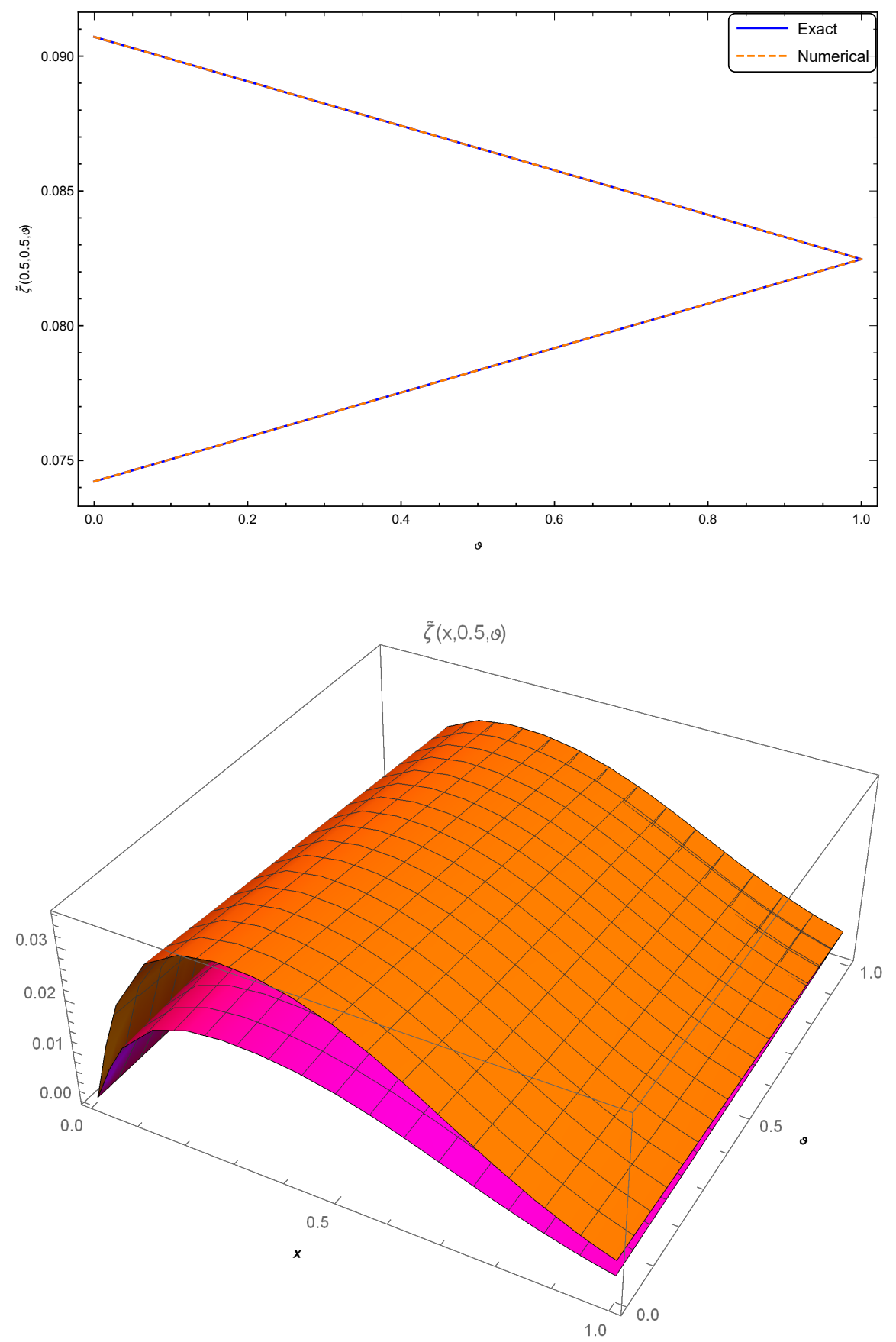

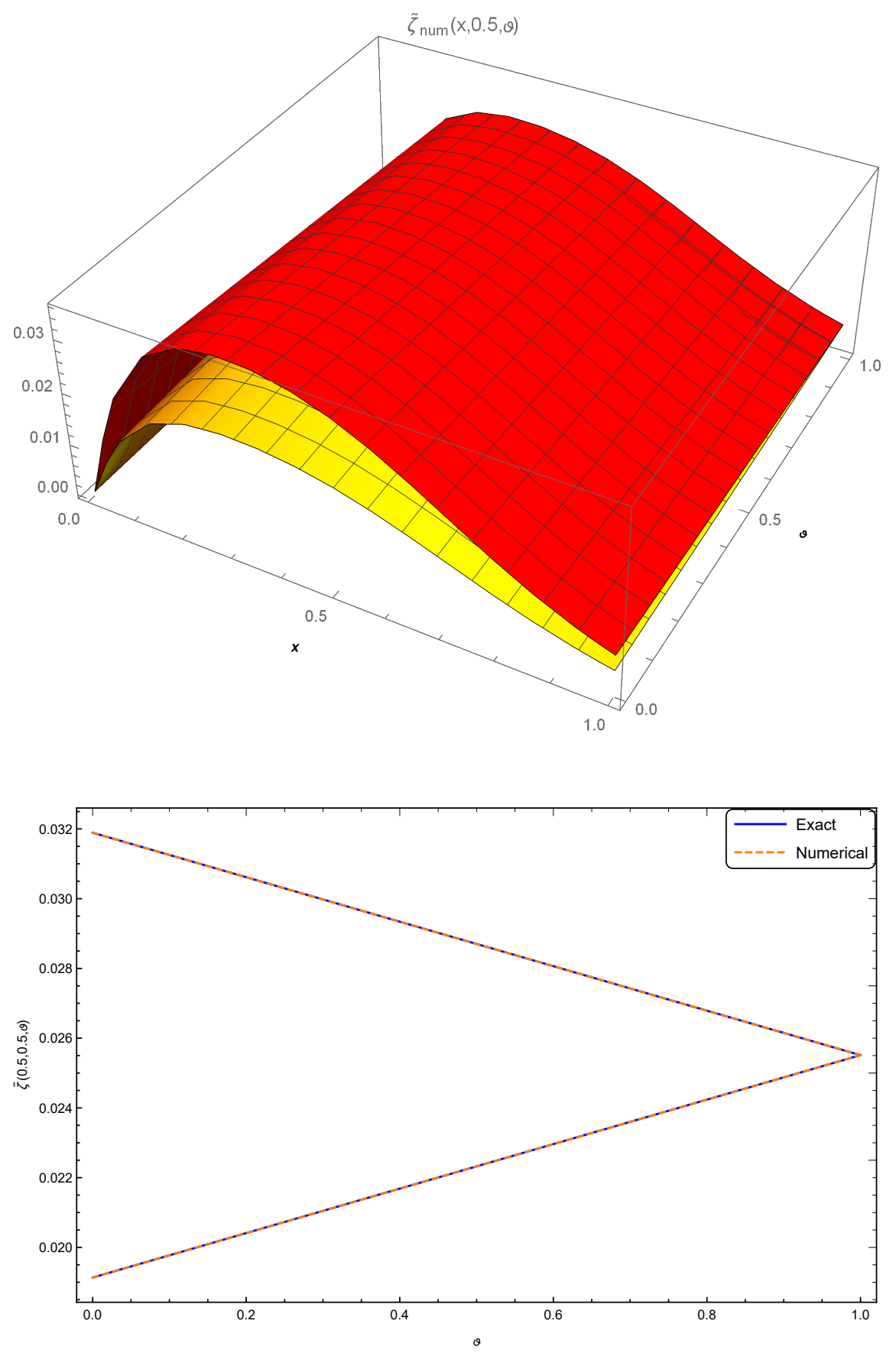


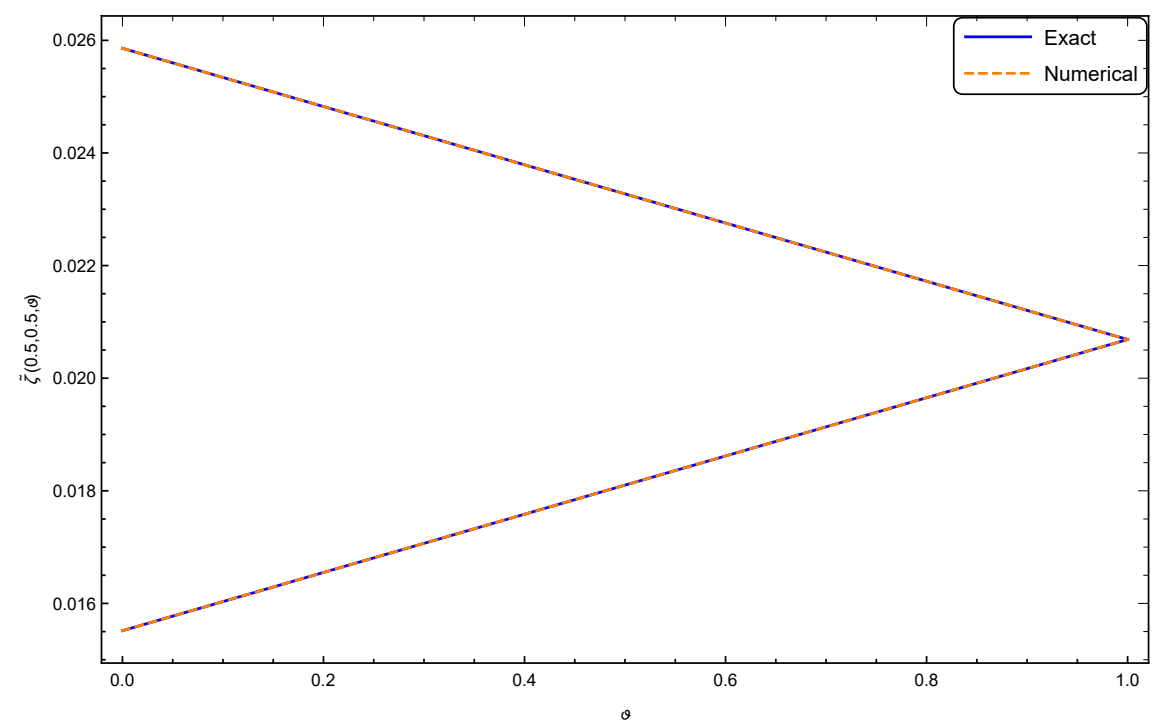

